\title{
High birth weight is a risk factor of dental caries increment during adolescence in Sweden*
}

\author{
Annika Julihn ${ }^{1,2 \#}$, Ulrika Molund ${ }^{1}$, Emma Drevsäter ${ }^{1}$, Thomas Modéer ${ }^{1}$ \\ ${ }^{1}$ Division of Pediatric Dentistry, Department of Dental Medicine, Karolinska Institute, Huddinge, Sweden \\ ${ }^{2}$ Specialist Clinic of Pediatric Dentistry, Specialist Dental Care in Västra Götaland, Göteborg, Sweden \\ Email: "annika.julihn@vgregion.se, umolund@hotmail.com, emma.drevsater@hotmail.com, thomas.modeer@ki.se
}

Received 29 October 2013; revised 30 November 2013; accepted 11 December 2013

Copyright (C) 2013 Annika Julihn et al. This is an open access article distributed under the Creative Commons Attribution License, which permits unrestricted use, distribution, and reproduction in any medium, provided the original work is properly cited.

\begin{abstract}
This study aimed to assess whether birth weight is associated with dental caries during the teenage period. In this register-based cohort study, all children of 13 yrs of age $(n=18,142)$ who resided in the county of Stockholm, Sweden, in 2000 were included. The cohort was followed until individuals were 19 yrs of age. Information regarding dental caries was collected from the Public Health Care Administration in Stockholm. Data concerning prenatal and perinatal factors and parental socio-demographic determinants were collected from the Swedish Medical Birth Register and National Registers at Statistics Sweden. The final logistic regression model showed that birth weight $(\geq 4000 \mathrm{~g}$ ), adjusted for potential confounders, was significantly associated with caries increment (DMFT $\geq 1$ ) between 13 and 19 yrs of age (OR: 1.29, $95 \% \mathrm{CI}=1.13-1.48)$. The relatively enhanced risk OR was further increased from 1.29 to 1.52 in subjects with birth weight $(\geq 4600$ g). On the contrary, subjects with birth weight $(<2500$ g) exhibited a significantly lower risk (OR: $0.67,95 \% \mathrm{CI}=0.50-0.89$ ) for exhibiting caries experience (DMFT $\geq 4$ ) at 19 yrs of age. In conclusion, birth weight can be regarded as a predictor for dental caries and birth weight $(\geq \mathbf{4 0 0 0}$ g) is especially a risk factor for caries increment during adolescence.
\end{abstract}

Keywords: Adolescents; Birth Weight; Cohort Study; Dental Caries; Longitudinal Study; Predictor; Risk Assessment; Risk Factor

\section{INTRODUCTION}

Birth weight in children has increased during the last two

"Conflicts of Interest: The authors declare no conflict of interest.

${ }^{*}$ Corresponding author. decades in many developed countries [1-4] despite an increased number of preterm births $[5,6]$. One explanation is an increasing proportion of infants born with high birth weight $[6,7]$. In approximately $10 \%$ of deliveries, the fetus exhibits birth weight higher than 4000 grams [8].

Fetal growth is initially autonomous but later more dependent on the flow of nutrients across the placenta. Viral infections as well as various maternal diseases such as diabetes and hypertension, and maternal life style factors including smoking have an impact on fetus growth, thereby affecting the birth weight of the child [9-11]. In clinical studies, several maternal anthropometric characteristics have been demonstrated to be positively associated with increased fetal growth, such as a maternal body mass index (BMI), and excessive weight gain during pregnancy $[11,12]$.

In recent years, the relationship between birth weight of the child and the risk for development of chronic diseases as adults has been frequently discussed. It has been shown that infants born with low birth weight $(<2500 \mathrm{~g})$ have a higher risk later in life of developing diabetes [13-15] or coronary heart diseases [16]. In addition, children with a high birth weight $(\geq 4000 \mathrm{~g})$ are reported to exhibit a higher prevalence of overweight during adolescence [17] as well as an increased risk of developing obesity $[18,19]$, diabetes $[13,14]$ or cancer $[20-22]$ later in life.

The relationship between birth weight and oral conditions has mostly been addressed in infants with low birth weight. There are several clinical studies demonstrating enhanced frequency of molar-incisor hypomineralization (MIH), gingival inflammation and behavioral management problems [23-27] in children with low birth weight. Most of the studies state that there is no relationship between low birth weight and the development of dental caries [28-31], although conflicting results are available $[32,33]$. The only study to the knowledge of the authors 
focused on children with high birth weight and demonstrated a weak association between dental caries and high birth weight in 5-year-old children [34]. Furthermore, the parameter apgar score, which reflects not only labor and delivery but also the condition during prenatal life, is reported to be associated with dental caries in 5-year-old children [35].

In a cohort of teenagers, this study recently identified maternal overweight in the first trimester as a risk factor for caries increment in their offspring between 13 to 19 years of age [36]. Overweight mothers and mothers with high gestational weight gain are at risk to deliver infants with high birth weight $[4,10]$ who exhibit a higher risk for developing obesity during childhood [17,18]. In a cross sectional study, we previously reported a close relationship between obesity and the occurrence of dental caries in adolescence [37]. The link between obesity and dental caries might be caused by the lower salivary flow rate $(\mathrm{ml} / \mathrm{min})$ demonstrated in the obese subjects compared with normal weight subjects [37]. In light of these findings, it was hypothesized that birth weight might be associated with dental caries later in life. Therefore, the current register-based cohort study of 13 and 19-year-old adolescents was undertaken to address whether their birth weight is associated with dental caries later in life.

\section{MATERIAL AND METHOD}

\subsection{Study Design}

The present study was designed as a retrospective longitudinal register-based cohort study and was based on information collected from data sources at the Public Health Care Administration in Stockholm, as well as from National Registers at the National Board of Health and Welfare and at the Central Bureau of Statistics Sweden (SCB). The study was approved by the Regional Ethical Board in Stockholm, Sweden, and the study protocol was approved by the Swedish Data Inspection Board, a Swedish federal agency that serves as an institutional review board for database linkages. Data was collected on dental caries, prenatal and perinatal factors, as well as on socio-demographic determinants.

\subsection{Subjects}

All 13-yr-old adolescents $(n=18,142)$ who resided in the county of Stockholm, Sweden, in the year 2000 were included in the study. This cohort was followed until the individuals were 19 yrs of age. During this period, the subjects received regular dental check-ups either from the Public Dental Health Service, private practitioners, or at the Division of Pediatric Dentistry, Department of Dental Medicine, at the Karolinska Institute, Stockholm. A total of 15,538 adolescents (7810 boys and 7728 girls) had clinical as well as radiographic dental examinations at both 13 and 19 yrs of age. The sample attrition rate was $14 \%$ and the most common reason for sample attrition was that the individual had moved out of the area. Of the examined subjects $(\mathrm{n}=15,538)$, information about birth weight or not was collected in 13,808 and thus constituted the final study cohort.

\subsection{Population-Based Registries}

The registers' usefulness in epidemiological research is facilitated by the Personal Identification Number (PIN), which is a 10-digit number unique to all residents and recorded in all health and census registers [38]. The PIN permits linkage of each individual between different registries. In the present study, information from the Medical Birth Register (MBR), the Total Population Register (TPR), the Total Enumeration Income Register, and the Education Register were used. Information about the registers and register linkages have previously been described [36].

\subsubsection{The Medical Birth Register (MBR)}

Mothers-to-be are followed from their first visit at the public maternity health-care clinic (usually between 8 and 10 weeks gestation), throughout their pregnancy to delivery and $8-12$ weeks post delivery. The register's quality has been evaluated three times: in 1976, 1988, and in 2001 [39,40]. The following variables were collected from the MBR; gender, gestational weeks, birth weight, congenital malformations, parity, maternal age, smoking habits during early pregnancy, and the mother's height and weight at the first visit to the public maternity health-care clinic as well as at delivery. The Body Mass Index (BMI) was calculated and analyzed according to whether the mother was overweight $(\mathrm{BMI} \geq 25.00)$ or not (BMI < 24.99). On the basis of the mother's weight in early pregnancy and at delivery, the variable "gestational weight gain" was calculated and further dichotomized and analyzed in two groups; $\leq 20 \mathrm{~kg}$ and $>20.0 \mathrm{~kg}$. The variable "birth weight" was categorized into eight subgroups according to 500 gram intervals. Children with a birth weight more or equal to 5000 grams $(n=43)$ were added to the subgroup of " $\geq 4500$ g". Each subgroup was then analyzed in relation to caries experience at 13 and 19 yrs of age as well as total caries increment between 13 and 19 yrs and presented in Table 1. In the logistic regression analyses, low birth weight $(<2500$ grams) and high birth weight ( $\geq 4000$ grams) were analyzed separately. A reference group "normal birth weight" was calculated based on the distribution of birth weight. The range for normal birth weight was estimated to be between $25 \%$ and $75 \%$ of the subjects. Based on this, the normal birth weight range was found to be between 3150 and 3815 grams. Remaining variables col- 
Table 1. Dental caries at 13 and 19 yrs of age in relation to birth weight.

\begin{tabular}{cccc}
\hline Birth weight & $\begin{array}{c}\text { DMFT } \\
13 \mathrm{yrs} \\
\text { Mean SD }\end{array}$ & $\begin{array}{c}\text { DMFT-increment } \\
13-19 \mathrm{yrs} \\
\text { Mean SD }\end{array}$ & $\begin{array}{c}\text { DMFT } \\
19 \mathrm{yrs} \\
\text { Mean SD }\end{array}$ \\
\hline $\begin{array}{c}<1500 \mathrm{~g} \\
\mathrm{n}=86\end{array}$ & $0.71,1.23$ & $2.06,2.94$ & $2.77,3.25$ \\
$\begin{array}{c}1500-1999 \mathrm{~g} \\
\mathrm{n}=127\end{array}$ & $0.91,1.60$ & $2.13,2.82$ & $3.05,3.51$ \\
$\begin{array}{c}2000-2499 \mathrm{~g} \\
\mathrm{n}=408\end{array}$ & $1.32,1.84$ & $2.10,2.77$ & $3.42,3.41$ \\
$2500-2999 \mathrm{~g}$ & $1.24,1.82$ & $2.14,2.97$ & $3.38,3.60$ \\
$\mathrm{n}=1606$ & & & \\
$3000-3499 \mathrm{~g}$ & $1.26,1.81$ & $2.00,2.88$ & $3.19,3.44$ \\
$\mathrm{n}=4768$ & & & \\
$3500-3999 \mathrm{~g}$ & $1.20,1.77$ & $2.09,2.88$ & $3.22,3.43$ \\
$\mathrm{n}=4682$ & & & \\
$4000-4499 \mathrm{~g}$ & $1.28,1.78$ & $2.03,2.85$ & $3.31,3.43$ \\
$\mathrm{n}=1768$ & & & $3.75,3.69$ \\
$\geq 4500 \mathrm{~g}$ & $1.54,2.13$ & $2.21,2.78$ & \\
$\mathrm{n}=363$ & & &
\end{tabular}

DMFT $(\mathrm{D}=$ decayed, $\mathrm{M}=$ missing, $\mathrm{F}=$ filled, $\mathrm{T}=$ teeth $) ; \mathrm{SD}=$ standard deviation; $\mathrm{g}=$ gram.

lected from the MBR were dichotomized in the statistical analyses, see Table 2.

\subsubsection{The Register of the Total Population}

This register is kept by Statistics Sweden. From the Register of the Total Population, the following variables were collected; maternal country of birth and marital status in 2005. In the statistical analysis, both variables were dichotomized (Table 2).

\subsubsection{The Total Enumeration Income Register}

Data on individuals' annual income tax, founded on income tax returns and tax-authority decisions, is collected by the National Swedish Tax Board. The Board then sends summary statistics to Statistics Sweden. From this register, information regarding the family's income and receipt of social-welfare allowance in 2005 was collected. Both variables were dichotomized and family income expressed as low income (less or equal to $25 \%$ of the lowest income range or high income (more than $25 \%$ of the lowest income range) in the statistical analysis (Table 2).

\subsubsection{The Education Register}

Data on education was obtained from the Education Register. In the statistical analysis, the variable "educational level" was divided according to years of schooling as: Low ( $\leq 9$ years), intermediate (10 - 12 years) and high (>12 years), (Table 2$)$.

\subsection{Data Collection Concerning Dental Caries}

In Stockholm, data on manifest caries lesions (based on clinical and radiographic examination) in children and adolescents is sent from the Public Dental Health Service, private practitioners, and the Division of Pediatric Dentistry, Department of Dental Medicine at the Karolinska Institute to the Public Health Care Administration and is analyzed at ages 3, 7, 13, and $19 \mathrm{yrs}$ of age. Since the year 2000, all this data has been linked to the PIN. The registration sheets of 13 and 19-yr-old children consist of the following caries counts: DT $=$ Decayed Teeth, MT = Missing Teeth, FT $=$ Filled Teeth, DSa $=$ Decayed Surfaces approximal and FSa $=$ Filled Surfaces approximal. Manifest caries was recorded on smooth surfaces as the minimal level that can be verified as a cavity and detectable by probing, and in fissures by a catch of the probe under slight pressure. Approximal caries on the radiographs was recorded as manifest caries when the lesion clearly extends into the dentin. For this study, the caries experience at 19 yrs of age and total caries increment between 13 and 19 yrs of age, using the DFT-indices, was used as the outcome in the statistical analyses.

The dental caries file of the study cohort was sent from the Public Health Care Administration to the SCB, where the data file was linked with the registers from Statistics Sweden and Swedish National Health and Welfare. The key to identify individuals was kept within the SCB and was not disclosed to the investigators.

\subsection{Statistical Analysis}

Data analyses were carried out using the Statistical Package for the Social Sciences (SPSS, version 21.0). For analyzing the data, frequency tables, cross tables and logistic regression were used. The odds ratios (OR) with $95 \% \mathrm{CI}$ were used as estimates of the effects.

Total caries increment (DMFT $\geq 1)$ between 13 and 19 yrs of age and caries experience (DMFT $\geq 1$, DMFT $\geq 4$ ) at $19 \mathrm{yrs}$ of age were used as outcome in the logistic regression analyses.

In a univariate analysis, the key exposure "birth weight" was analyzed as the continuous variable and potential confounders as categorical variables. In a multivariate analysis, "high birth weight" $(\geq 4000)$ was analyzed with "normal birth weight" (3150 - $3815 \mathrm{~g})$ as a reference and total caries increment (DMFT $\geq 1)$ as the outcome. To analyze "high birth weight" as a potential risk factor for total caries increment between 13 and 19 yrs of age, the variable was adjusted for confounders. The confounders for inclusion in the models were selected using a combination of methods, i.e. based on their association with the outcome as well as based on their association with the exposure and subsequently their influence on the outcome. All the variables were 
Table 2. Univariate logistic regression analysis with pre-, perinatal- and sociodemographic factors as exposure and caries experience $(\mathrm{DMFT} \geq 1)$ at $19 \mathrm{yrs}$ of age as outcome.

\begin{tabular}{|c|c|c|c|}
\hline Variables & $\begin{array}{c}\text { Subject with DMFT } \geq 1 \\
(\mathrm{n}=11605) / \text { total number of participants } \\
(\mathrm{n}=15538)\end{array}$ & Odds ratio; $95 \% \mathrm{CI}$ & P-value \\
\hline \multicolumn{4}{|l|}{ Child characteristics } \\
\hline Gender Female & $5757 / 7728$ & 1.00 & \\
\hline Male & $5762 / 7810$ & $0.96 ; 0.90-1.04$ & 0.298 \\
\hline Gestational weeks $>36$ weeks & $9624 / 14747$ & 1.00 & \\
\hline$\leq 36$ weeks & $584 / 791$ & $0.98 ; 0.84-1.16$ & 0.842 \\
\hline Birth weight $317-5760 \mathrm{~g}$ & $11605 / 15538$ & & 0.013 \\
\hline \multicolumn{4}{|l|}{ Congenital malformation } \\
\hline No & $9959 / 15145$ & 1.00 & \\
\hline Yes & $291 / 393$ & $0.99 ; 0.79-1.25$ & 0.967 \\
\hline Parity 1 - 2 & $8112 / 12877$ & 1.00 & \\
\hline$\geq 3$ & $2138 / 2661$ & $1.54 ; 1.39-1.71$ & $<0.001$ \\
\hline \multicolumn{4}{|l|}{ Maternal characteristics } \\
\hline Age $\geq 29 \mathrm{yrs}$ & $5024 / 8356$ & 1.00 & \\
\hline$<29 \mathrm{yrs}$ & $5226 / 7182$ & $0.86 ; 0.80-0.93$ & $<0.001$ \\
\hline Country of birth Sweden & $8164 / 11526$ & 1.00 & \\
\hline Born abroad & $3227 / 4012$ & $1.54 ; 1.41-1.68$ & $<0.001$ \\
\hline Marital status 2005 Married & $6992 / 9572$ & 1.00 & \\
\hline Not married & $4613 / 5966$ & $1.26 ; 1.17-1.36$ & $<0.001$ \\
\hline \multicolumn{4}{|l|}{ Smoked in early pregnancy } \\
\hline No & $6515 / 12277$ & 1.00 & \\
\hline Yes & $2604 / 3261$ & $1.55 ; 1.40-1.71$ & $<0.001$ \\
\hline BMI in early pregnancy $0-24.99$ & $5606 / 14413$ & 1.00 & \\
\hline$\geq 25.00$ & $883 / 1125$ & $1.39 ; 1.20-1.62$ & $<0.001$ \\
\hline BMI at delivery 0 - 24.99 & $1873 / 8740$ & 1.00 & \\
\hline$\geq 25.00$ & $5063 / 6798$ & $1.21 ; 1.10-1.34$ & $<0.001$ \\
\hline Gestational weight gain $0-20.0 \mathrm{~kg}$ & $6241 / 14119$ & 1.00 & \\
\hline$>20.0 \mathrm{~kg}$ & $1094 / 1419$ & $1.27 ; 1.11-1.45$ & $<0.001$ \\
\hline Educational level $2005>12 \mathrm{yrs}$ & $4694 / 6677$ & 1.00 & \\
\hline $10-12 \mathrm{yrs}$ & $5087 / 6705$ & $1.33 ; 1.23-1.43$ & $<0.001$ \\
\hline$\leq 9 \mathrm{yrs}$ & $1824 / 2156$ & $2.32 ; 2.04-2.64$ & $<0.001$ \\
\hline Income 2005 High income range ( $>25 \%)$ & $9043 / 12338$ & 1.00 & \\
\hline Low income range $(\leq 25 \%)$ & $2562 / 3200$ & $1.46 ; 1.33-1.61$ & $<0.001$ \\
\hline \multicolumn{4}{|l|}{ Social welfare allowance 2005} \\
\hline No & $10775 / 14568$ & 1.00 & \\
\hline Yes & $830 / 970$ & $2.09 ; 1.74-2.51$ & $<0.001$ \\
\hline
\end{tabular}

${ }^{*}=$ continuous variable.

classified (as shown in Table 2), and then entered into the multivariate analyses as independent variables. The final logistic regression analysis began with a full model and the model was then reduced by removing, one by one, insignificant covariates until only significant covariates persisted (Table 3). 
Table 3. Final multivariate logistic regression analysis with total caries increment $(\mathrm{DMFT} \geq 1)$ between 13 and $19 \mathrm{yrs}$ of age as outcome and high birth weight $(\geq 4000 \mathrm{~g})$ as key exposure.

\begin{tabular}{|c|c|c|c|}
\hline Variables & OR & $\begin{array}{c}95 \% \text { CI } \\
\text { Lower Upper }\end{array}$ & P-value \\
\hline \multicolumn{4}{|l|}{ Key variable } \\
\hline $\begin{array}{l}\text { High birth weight } \\
\begin{array}{c}3150-3815 \mathrm{~g} \\
(\mathrm{n}=4318)\end{array}\end{array}$ & 1.00 & & \\
\hline$\geq 4000 \mathrm{~g}(\mathrm{n}=1391)$ & 1.29 & $1.13,1.48$ & $<0.001$ \\
\hline \multicolumn{4}{|l|}{ Adjusted for } \\
\hline Parity $1-2$ & 1.00 & & \\
\hline$\geq 3$ & 1.19 & $1.03,1.39$ & 0.022 \\
\hline \multicolumn{4}{|l|}{ Maternal characteristics } \\
\hline Country of birth Sweden & 1.00 & & \\
\hline Born abroad & 1.17 & $1.01,1.37$ & 0.038 \\
\hline \multicolumn{4}{|l|}{ Smoked in early pregnancy } \\
\hline No & 1.00 & & \\
\hline Yes & 1.29 & $1.13,1.49$ & $<0.001$ \\
\hline \multicolumn{4}{|l|}{ BMI in early pregnancy } \\
\hline $0-24.99$ & 1.00 & & \\
\hline$\geq 25.00$ & 1.23 & $1.04,1.46$ & 0.016 \\
\hline \multicolumn{4}{|l|}{ Marital status 2005} \\
\hline Married & 1.00 & & \\
\hline Not married & 1.13 & $1.01,1.27$ & 0.037 \\
\hline \multicolumn{4}{|l|}{ Educational level 2005} \\
\hline$>12$ yrs & 1.00 & & $<0.001$ \\
\hline $10-12$ yrs & 1.21 & $1.07,1.36$ & 0.002 \\
\hline$\leq 9 \mathrm{yrs}$ & 1.64 & $1.34,2.02$ & $<0.001$ \\
\hline \multicolumn{4}{|c|}{ Social welfare allowance 2005} \\
\hline No & 1.00 & & \\
\hline Yes & 1.63 & $1.16,2.30$ & 0.003 \\
\hline
\end{tabular}

The key exposure "birth weight" was also analyzed as either "low birth weight" $(<2500 \mathrm{~g})$ or "high birth weight" $(\geq 4000)$ according to the magnitude, with "normal birth weight" (3150 - 3815 g) as the reference (Tables 4 and 5). Each cut-off level was analyzed separately in a multivariate logistic regression analysis with total caries increment (DMFT $\geq 1$ ), caries experience (DMFT $\geq 1$ ) and caries experience (DMFT $\geq 4$ ) as outcome. In these analyses, the key exposure was adjusted for potential confounders (as shown in Table 2).

\section{RESULTS}

Of the final cohort $(n=13,808), 4.5 \%(n=621)$ were born with a birth weight less than 2500 grams and 15.4\% $(n=2131)$ exhibited a birth weight of 4000 grams or more. In Table 1, the mean value and standard deviation of caries experience at 13 yrs of age, total caries increment between 13 and 19 yrs of age, and caries experience at $19 \mathrm{yrs}$ of age are described in relation to subgroups of birth weight. The lowest mean values of caries experience (DMFT) at both 13 and 19 yrs of age were seen among subjects born with a birth weight of less than 1500 grams and the highest mean values were seen among subjects born with a birth weight of 4500 grams or more (Table 1).

\subsection{Univariate Analysis}

In the univariate logistic regression analysis, the key exposure "birth weight" was analyzed as a continuous variable and all covariates as categorical variables. The analyses were performed with caries experience (DMFT $\geq 1$ ) at 19 yrs of age, as a dependent variable, and showed that "birth weight", as a continuous variable, was significantly associated with the outcome $(p=0.013)$, (Table 2). In addition, the following potential confounders were also significantly associated with the outcome: Parity, maternal age, country of birth, marital status, smoking during early pregnancy, BMI in early pregnancy, BMI at delivery, gestational weight-gain, educational level, income and receiving social welfare allowance (Table 2).

\subsection{Multivariate Analysis}

In a multivariate logistic regression analysis, the association between high birth weight $(\geq 4000 \mathrm{~g})$ and the total caries increment (DMFT $\geq 1$ ) between 13 and 19 years of age was tested. At the start, all variables in Table 2 were included in the model. In the final model, only significant covariates persisted. The results showed that "high birth weight" was significantly associated with the outcome (OR 1.29; 95\% CI = 1.13 - 1.48). Remaining significant variables in the final model except for "high birth weight" were parity, country of birth, smoked during early pregnancy, BMI in early pregnancy, gestational weight-gain, marital status, maternal educational level and family receiving social welfare allowance (Table 3).

\subsection{Dental Caries in Relation to the Magnitude of Low Birth Weight}

In this statistical analysis, the total caries increment between 13 and 19 yrs of age as well as caries experience at 19 yrs of age in relation to the magnitude of low birth weight was studied. All analyses were adjusted for possible confounders presented in Table 2. After adjustments, the results showed that children born with a birth 
Table 4. Logistic regression analysis with the magnitude of low birth weight as exposure and caries experience at 19 yrs of age and total caries increment between 13 and 19 yrs as an outcome.

\begin{tabular}{|c|c|c|c|c|c|}
\hline Caries indices & $\begin{array}{c}\text { Birth weight }<\mathbf{2 5 0 0} \text { g } \\
\text { OR } 95 \% \text { CI }\end{array}$ & $\begin{array}{c}\text { Birth weight }<\mathbf{2 1 0 0} \text { g } \\
\text { OR } 95 \% \text { CI }\end{array}$ & $\begin{array}{c}\text { Birth weight }<\mathbf{2 0 0 0} \mathbf{g} \\
\text { OR } 95 \% \text { CI }\end{array}$ & $\begin{array}{c}\text { Birth weight }<\mathbf{1 8 0 0} \text { g } \\
\text { OR } 95 \% \text { CI }\end{array}$ & $\begin{array}{c}\text { Birth weight }<\mathbf{1 7 0 0} \mathrm{g} \\
\text { OR } 95 \% \mathrm{CI}\end{array}$ \\
\hline \multicolumn{6}{|l|}{ Caries experience } \\
\hline$(\mathrm{DMFT} \geq 1)$ & $\mathrm{n}=455$ & $\mathrm{n}=180$ & $\mathrm{n}=148$ & $\mathrm{n}=97$ & $\mathrm{n}=76$ \\
\hline Unadjusted & $0.97,0.80-1.17$ & $0.84,0.65-1.08$ & $0.80,0.60-1.08$ & $0.76,0.53-1.09$ & $0.75,0.50-1.11$ \\
\hline Adjusted & $0.84,0.68-1.03$ & $0.75,0.55-1.03$ & $0.69,0.49-0.96$ & $0.63,0.42-0.94$ & $0.60,0.38-0.93$ \\
\hline$($ DMFT $\geq 4)$ & $\mathrm{n}=232$ & $\mathrm{n}=83$ & $\mathrm{n}=69$ & $\mathrm{n}=48$ & $\mathrm{n}=36$ \\
\hline Unadjusted & $0.98,0.82-1.16$ & $0.80,0.62-1.05$ & $0.79,0.59-1.05$ & $0.84,0.59-1.19$ & $0.78,0.52-1.16$ \\
\hline Adjusted & $0.67,0.50-0.89$ & $0.50,0.30-0.81$ & $0.51,0.30-0.89$ & $0.71,0.38-1.32$ & $0.71,0.34-1.46$ \\
\hline \multicolumn{6}{|l|}{ Caries increment } \\
\hline$($ DMFT $\geq 1)$ & $\mathrm{n}=398$ & $\mathrm{n}=161$ & $\mathrm{n}=135$ & $\mathrm{n}=90$ & $\mathrm{n}=69$ \\
\hline Unadjusted & $1.09,0.92-1.29$ & $1.08,0.83-1.40$ & $1.05,0.79-1.40$ & $1.05,0.75-1.49$ & $0.98,0.67-1.43$ \\
\hline Adjusted & $0.97,0.81-1.17$ & $1.03,0.77-1.37$ & $0.98,0.72-1.35$ & $0.91,0.62-1.34$ & $0.83,0.54-1.26$ \\
\hline
\end{tabular}

Adjusted for prenatal and perinatal factors (gender, gestational weeks, congenital malformation, parity, maternal age, maternal smoking during early pregnancy, BMI in early pregnancy, BMI at delivery, weight-gain during pregnancy), and maternal sociodemographic factors (civil status, maternal country of birth, maternal educational level, maternal income level and mother receiving social welfare allowance).

Table 5. Logistic regression analysis with the magnitude of high birth weight as exposure and caries experience at 19 yrs of age and caries increment between 13 and 19 yrs of age as an outcome.

\begin{tabular}{|c|c|c|c|c|c|}
\hline Caries indices & $\begin{array}{c}\text { Birth weight } \geq \mathbf{4 0 0 0} \mathbf{g} \\
\text { OR } 95 \% \mathrm{CI}\end{array}$ & $\begin{array}{c}\text { Birth weight } \geq \mathbf{4 2 0 0} \mathbf{g} \\
\text { OR } 95 \% \text { CI }\end{array}$ & $\begin{array}{c}\text { Birth weight } \geq \mathbf{4 4 0 0} \mathbf{g} \\
\text { OR } 95 \% \text { CI }\end{array}$ & $\begin{array}{c}\text { Birth weight } \geq \mathbf{4 5 0 0} \text { g } \\
\text { OR } 95 \% \text { CI }\end{array}$ & $\begin{array}{c}\text { Birth weight } \geq \mathbf{4 6 0 0} \mathbf{g} \\
\text { OR } 95 \% \text { CI }\end{array}$ \\
\hline \multicolumn{6}{|c|}{ Caries experience } \\
\hline$($ DMFT $\geq 1)$ & $n=1634$ & $\mathrm{n}=867$ & $\mathrm{n}=416$ & $\mathrm{n}=286$ & $\mathrm{n}=192$ \\
\hline Unadjusted & $1.16,1.04-1.30$ & $1.20,1.03-1.39$ & $1.22,0.99-1.51$ & $1.31,1.01-1.70$ & $1.54,1.11-2.15$ \\
\hline Adjusted & $1.24,1.09-1.40$ & $1.24,1.06-1.46$ & $1.28,1.02-1.60$ & $1.35,1.03-1.79$ & $1.50,1.05-2.13$ \\
\hline$($ DMFT $\geq 4)$ & $\mathrm{n}=842$ & $\mathrm{n}=458$ & $\mathrm{n}=220$ & $\mathrm{n}=154$ & $\mathrm{n}=103$ \\
\hline Unadjusted & $1.07,0.97-1.18$ & $1.13,0.99-1.28$ & $1.14,0.95-1.36$ & $1.21,0.98-1.50$ & $1.27,0.98-1.65$ \\
\hline Adjusted & $1.13,1.01-1.26$ & $1.17,1.02-1.35$ & $1.20,0.99-1.46$ & $1.27,1.01-1.60$ & $1.34,1.01-1.77$ \\
\hline \multicolumn{6}{|l|}{ Caries increment } \\
\hline$(\mathrm{DMFT} \geq 1)$ & $\mathrm{n}=1391$ & $\mathrm{n}=743$ & $\mathrm{n}=362$ & $\mathrm{n}=248$ & $\mathrm{n}=166$ \\
\hline Unadjusted & $1.14,1.03-1.27$ & $1.19,1.04-1.36$ & $1.27,1.05-1.53$ & $1.31,1.05-1.65$ & $1.44,1.09-1.92$ \\
\hline Adjusted & $1.29,1.13-1.48$ & $1.30,1.09-1.55$ & $1.38,1.09-1.76$ & $1.48,1.12-1.91$ & $1.52,1.08-2.04$ \\
\hline
\end{tabular}

Adjusted for prenatal and perinatal factors (gender, gestational weeks, congenital malformation, parity, maternal age, maternal smoking during early pregnancy, BMI in early pregnancy, BMI at delivery, weight-gain during pregnancy), and maternal sociodemographic factors (marital status, maternal country of birth, maternal educational level, maternal income level and mother receiving social welfare allowance).

weight less than 2000 grams exhibited a statistically significant negative association with caries experience $(\mathrm{DMFT} \geq 1)$ at $19 \mathrm{yrs}$ of age (OR $0.69 ; 95 \% \mathrm{CI}=0.49$ 0.96), (Table 4). When the birth weight was less than 1600 grams, the variable "low birth weight" was no longer significant in the model. Further, when low birth weight was analyzed in relation to caries experience
(DMFT $\geq 4$ ), a statistical significant negative association was found in subjects born with a birth weight less than 2500 grams (OR 0.67; 95\% CI $=0.50-0.89$ ). Strongest negative association was seen at low birth weight less than 2100 grams (OR 0.50; 95\% CI $=0.30-0.81$ ), (Table 4). However, when the birth weight was less than 1800 grams the variable "low birth weight" was no 
longer significant in the model. Concerning total caries increment, no significant associations with low birth weight was found.

\subsection{Dental Caries in Relation to the Magnitude of High Birth Weight}

In Table 5, the total caries increment between 13 and 19 yrs of age as well as the caries experience at $19 \mathrm{yrs}$ of age was analyzed in relation to the magnitude of high birth weight. All analyses were adjusted for possible confounders presented in Table 2. After adjustments, the results showed that children born with a high birth weight more or equal to 4000 grams, exhibited a statisticcally significant positive association with caries experience (DMFT $\geq 1$ ) at $19 \mathrm{yrs}$ of age (OR 1.24; 95\% CI $=1.09-1.40)$, (Table 5). When high birth weight was analyzed at various cut-off levels; $\geq 4200 \mathrm{~g}, \geq 4400 \mathrm{~g}$, $\geq 4500 \mathrm{~g}$ and $\geq 4600 \mathrm{~g}$, the positive risk of exhibiting caries experience (DMFT $\geq 1)$ at 19 yrs of age was still significant. Further, the excess risk across the various cutoff levels increased up to a high birth weight more or equal to $4600 \mathrm{~g}(\mathrm{OR} 1.50 ; 95 \% \mathrm{CI}=1.05-2.13)$, (Table 5). However, when the birth weight was more or equal to 4700 grams the variable "high birth weight" was no longer significant in the model. High birth weight was also analyzed in relation to caries experience (DMFT $\geq$ 4). In this analysis, the excess risk of exhibiting caries was lower compared to the association between high birth weight and caries experience (DMFT $\geq 1$ ), (Table 5). In the next multivariate model, high birth weight was tested with total caries increment as the outcome. The results showed that high birth weight was significantly positive when associated with the outcome across all tested cut-off levels of high birth weight. Further, the excess risk was enhanced as the cut-off levels of high birth weight increased.

\section{DISCUSSION}

The novel finding demonstrates that birth weight $(\geq 4000$ $\mathrm{g}$ ) is associated with caries development later in life during adolescence. The risk of caries increment (DMFT $>1$ ) for infants born with a birth weight of 4000 grams or higher was 1.22 (OR) and increased positively with the magnitude of birth weight, adjusted for potential confounders like maternal and child characteristics including socioeconomic factors. Regarding infants with birth weight $(<2500 \mathrm{~g})$, we did not demonstrate any enhanced risk for dental caries development. However, low birth weight infants reveal a relatively lower risk for exhibiting one or more DMFT at 19 years of age compared with normal weight infants.

There is a great advantage of using population-based registers compared with common dental health surveys when identifying various risk factors for dental caries. In this study, we used the MBR register as our source of information. An advantage of using MBR is that it covers $\sim 97 \%-99 \%$ of deliveries in Sweden [40]. The quality of MBR has been evaluated with the conclusion that it is a valuable source of information for reproduction epidemiology $[39,40]$. The validity of information on prenatal factors used in the statistical analyses is probably accurate since the information was collected prospectively before birth. Furthermore, all information regarding the family was collected independently of the study outcome, which reduced problems with recall and interviewer bias. However, we were not able to include information on the weight of the subjects during the study period, when the adolescents were between 13 and 19 years of age. Consequently, it was not possible to adjust for the confounder "weight of the subject" in the multivariate model with caries increment as outcome.

Dental data was collected at 13 and 19 years of age from the Public Health Care Administration in the county of Stockholm and has been used in other registerbased studies with valid results [36,41]. In register-based studies, there is a risk of random errors because the diagnosis of manifest caries can sometimes be under-reported or over-reported due to several examiners. However, random errors are affected by increasing the size of the study and will be reduced to zero if a study becomes infinitely large [42]. In this study, the final study cohort consisted of 13,808 children and the risk of random error is, therefore, of minor importance.

We decided on a cut-off point of high caries experience (DMFT $\geq 4$ ) for both statistical and theoretical reasons. The population in the highest tertile of frequency distribution are those who attended dental services with more treatment need [43]. On the other hand, a child with DMFT equal to one may be considered as acceptable because dental caries is almost impossible to eradicate.

In a multivariate model, the association between birth weight and dental caries was controlled for various confounders like maternal characteristics in terms of age, country of birth, marital status, smoking habits, BMI early in pregnancy and at delivery, gestational weight gain, social welfare allowance, family income and educational level as well as the child characteristics like gestational weeks, congenital malformation and parity.

For the first time, this study demonstrates that birth weight $(\geq 4000 \mathrm{~g})$ is a risk factor for dental caries development later in life. This finding is interesting in light of previous discussions where dental caries experience might be biologically programmed in utero or early life [32], like other chronic diseases [44]. The mechanism behind the link between birth weight $(\geq 4000 \mathrm{~g})$ and dental caries development is unclear although there might be 
some factors of importance for predisposing such association. One explanation is that infants born with high birth weight have an increased risk for developing overweight or obesity during childhood $[17,18]$. Together with our previous finding of an association between obesity and dental caries in adolescents [37] the link between birth weight and dental caries found in our study might be confounded by an overrepresentation of adolescents with overweight or obesity within the group of infants with birth weight $(\geq 4000 \mathrm{~g})$. As previously pointed out, there was no information regarding the weight of the adolescents during the study period. Therefore, it was not possible to evaluate whether the weight of the subject was a confounder or not when analyzing the relationship between birth weight and caries increment in the multivariate model. Taken into account previous findings that obesity subjects might exhibit more dental caries compared to normal weight subjects [37], it is important in future clinical studies to control for the weight of the adolescents.

A potential mechanism explaining the link between obesity and dental caries might be the reduction of the salivary flow rate seen among obese subjects compared with normal weight adolescents [37]. The mechanism(s) behind the association between obesity and dental caries subjects might also be mediated by an alteration of the oral microflora during obesity. Due to decreased salivary flow in obese subjects, the oral biofilm might change in quality and/or quantity that contribute to an alteration in balance between demineralization and remineralization activity on the tooth surface. In a recent paper, we demonstrated that the subgingival microflora differs in obese teenagers compared with normal weight subjects [45]. We found approximately threefold higher levels of Phylum firmicutes whereas Streptococcus mutans was twofold higher in obese adolescents compared with normal weight adolescents.

One has to consider that we did not have any information regarding dietary habits or prevention measures given to the subjects. We can therefore not eliminate that the birth weight, as a risk factor for dental caries, can be biased, to some extent, by decreased prevention procedures, insufficient dietary habits or poorer oral hygiene among subjects with a high birth weight.

There might also be biological factors that partly can influence upon a foetus's immune response like maternal lifestyle factors [36] that in the long-term influences oral colonisation of caries related microorganisms [28] and thereby increase the risk for caries development.

Another interesting finding in this study was the negative association between low birth weight and caries experience at 19 yrs of age after taking into account potential confounding factors. Our finding, that low birth weight infants run a lower risk of developing caries compared to normal birth weight infants is in line with previous studies indicating that caries prevalence in primary teeth was lower among premature and very low birth weight infants compared to term and normal weight infants $[46,47]$. It is unclear what might causing the decreased caries experience $(\mathrm{DMFT} \geq 4)$ in adolescents with birth weight $(<2500 \mathrm{~g})$. One explanation could be closer monitoring of low birth weight children since infants born both short and thin have been found to be at greater risk for mortality and hospitalizations [48,49]. In addition, it has been shown that very low birth weight infants at 14 years had significantly more functional limitations and receive more coordinated care than the term adolescents [26]. In addition, caregivers were providing brushing assistance/supervision for the very low birth weight group for a significantly longer period than for normal birth weight infants [26].

Another possible explanation for the negative association between low birth weight and caries experience at 19 yrs of age is more frequent antibiotic use in our low birth weight group, due to many health problems among premature and very low birth weight children. The frequent use of antibiotics has been indicated as inhibiting the colonization of cariogenic bacteria [50] that may possibly explain the reduced caries experience in our very low birth weight group. Unfortunately, information regarding antibiotic use was not available and is therefore a limitation of this study.

\section{CONCLUSION}

In conclusion, birth weight can be regarded as a predictor for dental caries and birth weight $(\geq 4000 \mathrm{~g})$ is especially a risk factor for caries increment during adolescence and should be taken into consideration in the risk assessment. Furthermore, this study indicates that low birth weight infants do not run a higher risk of developing caries than other children in the permanent dentition.

\section{ACKNOWLEDGEMENTS}

This study was supported by grants from the Skaraborg County Council, the Swedish Dental Society, and the Swedish Patent Revenue Research Fund.

\section{REFERENCES}

[1] Meeuwisse, G. and Olausson, P.O. (1998) Increased birth weights in the Nordic countries. A growing proportion of neonates weigh more than four kilos. Lakartidningen, $\mathbf{9 5}$, 5488-5492.

[2] Lundqvist, E., Gottvall, K. and Kallén, K. (2013) Pregnancies, deliveries and newborn infants. The Swedish medical birth register 1973-2011. Official statistics of Sweden. Statistics - Health and Medical Care 2013. National Board of Health and Welfare. Article Number: 


\section{HS0107BR1202.}

[3] Power, C. (1994) National trends in birth weight: Implications for future adult disease. British Medical Journal, 308, 1270-1271.

http://dx.doi.org/10.1136/bmj.308.6939.1270

[4] Kramer, M.S., Morin, I., Yang, H., Platt, R.W., Usher, R., McNamara, H., Joseph, K.S. and Wen, S.W. (2002) Why are babies getting bigger? Temporal trends in fetal growth and its determinants. Journal of Pediatrics, 141, 538-542. http://dx.doi.org/10.1067/mpd.2002.128029

[5] Demissie, K., Rhoads, G.G., Ananth, C.V., Alexander, G.R., Kramer, M.S., Kogan, M.D. and Joseph, K.S. (2001) Trends in preterm birth and neonatal mortality among blacks and whites in the United States from 1989 to 1997. American Journal of Epidemiology, 154, 307-315. http://dx.doi.org/10.1093/aje/154.4.307

[6] Oken, E. (2013) Secular trends in birthweight. Nestlé Nutrition Institute Workshop Series, 71, 103-114. http://dx.doi.org/10.1159/000342576

[7] Surkan, P.J., Hsieh, C.C., Johansson, A.L., Dickman, P.W. and Cnattingius, S. (2004) Reasons for increasing trends in large for gestational age births. Obstetrics \& Gynecology, 104, 720-726. http://dx.doi.org/10.1097/01.AOG.0000141442.59573.cd

[8] Siega-Riz, A.M., Viswanathan, M., Moos, M.K., Deierlein, A., Mumford, S., Knaack, J., Thieda, P., Lux, L.J. and Lohr, K.N. (2009) A systematic review of outcomes of maternal weight gain according to the Institute of Medicine recommendations: Birthweight, fetal growth, and postpartum weight retention. American Journal of $\mathrm{Ob}$ stetrics \& Gynecology, 201, 339.e1-e14. http://dx.doi.org/10.1016/j.ajog.2009.07.002

[9] Kramer, M.S. (1987) Determinants of low birth weight: Methodological assessment and meta-analysis. Bulletin of the World Health Organization, 65, 663-737.

[10] Ehrenberg, H.M., Mercer, B.M. and Catalano, P.M. (2004) The influence of obesity and diabetes on the prevalence of macrosomia. American Journal of Obstetrics \& Gynecology, 191, 964-968.

http://dx.doi.org/10.1016/j.ajog.2004.05.052

[11] Ahlsson, F. (2008) Being born large for gestational age. Metabolic and epidemiological studies. Ph.D. Thesis, Uppsala University, Sweden.

[12] Hickey, C.A., Cliver, S.P., Goldenberg, R.L. and Blankson, M.L. (1992) Maternal weight status and term birth weight in first and second adolescent pregnancies. Journal of Adolescent Health, 13, 561-569. http://dx.doi.org/10.1016/1054-139X(92)90369-M

[13] Wei, J.N., Sung, F.C., Li, C.Y., Chang, C.H., Lin, R.S., Lin, C.C., Chiang, C.C. and Chuang, L.M. (2003) Low birth weight and high birth weight infants are both at an increased risk to have type 2 diabetes among schoolchilddren in Taiwan. Diabetes Care, 26, 343-348. http://dx.doi.org/10.2337/diacare.26.2.343

[14] Harder, T., Rodekamp, E., Schellong, K., Dudenhausen, J.W. and Plagemann, A. (2007) Birth weight and subsequent risk of type 2 diabetes: a meta-analysis. American Journal of Epidemiology, 165, 849-857. http://dx.doi.org/10.1093/aje/kwk071
[15] Johansson, S., Iliadou, A., Bergvall, N., dé Fairé, U., Kramer, M.S., Pawitan, Y., Pedersen, N.L., Norman, M., Lichtenstein, P. and Cnattingius, S. (2008) The association between low birth weight and type 2 diabetes: Contribution of genetic factors. Epidemiology, 19, 659-665. http://dx.doi.org/10.1097/EDE.0b013e31818131b9

[16] Barker, D.J. (2008) Human growth and cardiovascular disease. Nestle Nur Workshop Ser Pediatr Program, 61, 21-38. http://dx.doi.org/10.1159/000113163

[17] Rugholm, S., Baker, J.L., Olsen, L.W., Schack-Nielsen, L., Bua, J. and Sørensen, T.I. (2005) Stability of the association between birth weight and childhood overweight during the development of the obesity epidemic. Obesity Research, 13, 2187-2194. http://dx.doi.org/10.1038/oby.2005.271

[18] Wang, Y., Gao, E., Wu, J., Zhou, J., Yang, Q., Walker, M.C., Mbikay, M., Sigal, R.J., Nair, R.C. and Wen, S.W. (2009) Fetal macrosomia and adolescence obesity: Results from a longitudinal cohort study. International Journal of Obesity, 33, 923-928.

http://dx.doi.org/10.1038/ijo.2009.131

[19] Zhao, Y., Wang, S.F., Mu, M. and Sheng, J. (2012) Birth weight and overweight/obesity in adults: A meta-analysis. European Journal of Pediatrics, 171, 1737-1746. http://dx.doi.org/10.1007/s00431-012-1701-0

[20] Ekbom, A., Hsieh, C.C., Lipworth, L., Wolk, A., Pontén, J., Adami, H.O. and Trichopoulos, D. (1996) Perinatal characteristics in relation to incidence of and mortality from prostate cancer. British Medical Journal, 313, 337341. http://dx.doi.org/10.1136/bmj.313.7053.337

[21] Innes, K., Byers, T. and Schymura, M. (2000) Birth characteristics and subsequent risk for breast cancer in very young women. American Journal of Epidemiology, 152, 1121-1128. http://dx.doi.org/10.1093/aje/152.12.1121

[22] Risnes, K.R., Vatten, L.J., Baker, J.L., Jameson, K., Sovio, U., Kajantie, E., Osler, M., Morley, R., Jokela, M., Painter, R.C., Sundh, V., Jacobsen, G.W., Eriksson, J.G., Sørensen, T.I. and Bracken, M.B. (2011) Birthweight and mortality in adulthood: A systematic review and metaanalysis. International Journal of Epidemiology, 40, 647 661. http://dx.doi.org/10.1093/ije/dyq267

[23] Brogårdh-Roth, S., Stjernqvist, K. and Matsson, L. (2008) Dental behavioural management problems and dental caries prevalence in 3- to 6-year-old Swedish children born preterm. International Journal of Paediatric Dentistry, 18, 341-347. http://dx.doi.org/10.1111/j.1365-263X.2007.00884.x

[24] Arrow, P. (2009) Risk factors in the occurrence of enamel defects of the first permanent molars among schoolchilddren in Western Australia. Community Dentistry and Oral Epidemiology, 37, 405-415. http://dx.doi.org/10.1111/j.1600-0528.2009.00480.x

[25] Velló, M.A., Martinez-Costa, C., Catalá, M., Fons, J., Brines, J. and Guijarro-Martinez, R. (2010) Prenatal and neonatal risk factors for the development of enamel defects in low birth weight children. Oral Diseases, 16, 257-262. http://dx.doi.org/10.1111/j.1601-0825.2009.01629.x

[26] Nelson, S., Albert, J.M., Lombardi, G., Wishnek, S., 
Asaad, G., Kirchner, H.L. and Singer, L.T. (2010) Dental caries and enamel defects in very low birth weight adolescents. Caries Research, 44, 509-518. http://dx.doi.org/10.1159/000320160

[27] Brogårdh-Roth, S., Matsson, L. and Klingberg, G. (2011) Molar-incisor hypomineralization and oral hygiene in 10to-12-yr-old Swedish children born preterm. European Journal of Oral Sciences, 119, 33-39. http://dx.doi.org/10.1111/j.1600-0722.2011.00792.x

[28] Burt, B.A. and Pai, S. (2001) Does low birth weight increase the risk of caries? A systematic review. Journal of Dental Education, 65, 1024-1027.

[29] Shulman, J.D. (2005) Is there an association between low birth weight and caries in the primary dentition? Caries Research, 39, 161-167. http://dx.doi.org/10.1159/000084792

[30] Peres, M., de Oliviera Latorre Mdo, R., Sheiham, A., Peres, K.G., Barros, F.C., Hernandez, P.G., Maas, A.M.N., Romano, A.R. and Victora, C.G. (2005) Social and biological early life influences on severity of dental caries in children aged 6 years. Community Dentistry and Oral Epidemiology, 33, 53-63.

http://dx.doi.org/10.1111/j.1600-0528.2004.00197.x

[31] Saraiva, M.C., Chiga, S., Bettiol, H., Silva, A.A. and Barbieri, M.A. (2007) Is low birth weight associated with dental caries in permanent dentition? Paediatric and Perinatal Epidemiology, 21, 49-56. http://dx.doi.org/10.1111/j.1365-3016.2007.00782 1.x

[32] Nicolau, B., Marcenes, W., Bartley, M. and Sheiham, A. (2003) A life course approach to assessing causes of dental caries experience: The relationship between biological, behavioural, socio-economic and psychological conditions and caries in adolescents. Caries Research, 37, 319-326. http://dx.doi.org/10.1159/000072162

[33] Zheng, S., Deng, H. and Gao, X. (1998) Studies on developmental enamel defects in the primary dentition of children with histories of low birth weight and prematureity and their susceptibility to dental caries. Zhonghua Kou Qiang Yi Xue Za Zhi, 33, 270-272.

[34] Kay, E.J., Northstone, K., Ness, A., Duncan, K. and Crean, S.J. (2010) Is there a relationship between birthweight and subsequent growth on the development of dental caries at 5 years of age? A cohort study. Community Dentistry and Oral Epidemiology, 38, 408-414. http://dx.doi.org/10.1111/j.1600-0528.2010.00548.x

[35] Sanders, A.E. and Slade, G.D. (2010) Apgar score and dental caries risk in the primary dentition of five year olds. Australian Dental Journal, 55, 260-267. http://dx.doi.org/10.1111/j.1834-7819.2010.01232.x

[36] Julihn, A., Ekbom, A. and Modéer, T. (2009) Maternal overweight and smoking: Prenatal risk factors for caries development in offspring during the teenage period. European Journal of Epidemiology, 24, 753-762. http://dx.doi.org/10.1007/s10654-009-9399-7

[37] Modéer, T., Blomberg, C.C., Wondimu, B., Julihn, A. and Marcus, C. (2010) Association between obesity, flow rate of whole saliva, and dental caries in adolescents. Obesity (Silver Spring), 18, 2367-2373. http://dx.doi.org/10.1038/oby.2010.63
[38] Ludvigsson, J.F., Otterblad-Olausson, P., Pettersson, B.U. and Ekbom, A. (2009) The Swedish personal identity number: Possibilities and pitfalls in healthcare and medical research. European Journal of Epidemiology, 24, 659-667. http://dx.doi.org/10.1007/s10654-009-9350-y

[39] Cnattingius, S., Ericson, A., Gunnarskog, J. and Källén, B. (1990) A quality study of a Medical Birth Registry. Scandinavian Journal of Social Medicine, 18, 143-148.

[40] Källén, B., Källén, K., Edlund, M. and Otterblad-Olausson, P. (2002) Utvärdering av det svenska Medicinska födelseregistret (in Swedish). The National Board of Health and Welfare.

http://www.socialstyrelsen.se/Lists/Artikelkatalog/Attach ments/10961/2002-112-4_20021124.pdf

[41] Julihn, A., Ekbom, A. and Modéer, T. (2010) Migration background: A risk factor for caries development during adolescence. European Journal of Oral Sciences, 118, 618-625.

http://dx.doi.org/10.1111/j.1600-0722.2010.00774.x

[42] Rothman, K.J. (2002) Biases in study design. Epidemiology: An Introduction, 1st Edition, Oxford University Press, New York, 94-95.

[43] Davies, M.J., Spencer, A.J. and Slade, G.D. (1997) Trends in dental caries experience of schoolchildren in Australia —1977 to 1993. Australian Dental Journal, 42, 389-394. http://dx.doi.org/10.1111/j.1834-7819.1997.tb06083.x

[44] Barker, D.J.P. (1998) Mother, babies and health in later life. 2nd Edition, Churchill Livingstone, Edinburgh.

[45] Ziegler, C., Persson, G.R., Wondimu, B., Marcus, C., Sobko, T. and Modéer, T. (2012) Microbiota in the oral subgingival biofilm is associated with obesity in adolescence. Obesity (Silver Spring), 20, 157-164.

http://dx.doi.org/10.1038/oby.2011.305

[46] Gravina, D.B., Cruvinel, V.R., Azevedo, T.D., de Toledo, O.A. and Bezerra, A.C. (2006) Prevalence of dental caries in children born prematurely or at full term. Brazilian Oral Research, 20, 353-357. http://dx.doi.org/10.1590/S1806-83242006000400013

[47] Lai, P.Y., Seow, W.K., Tudehope, D.I. and Rogers, Y. (1997) Enamel hypoplasia and dental caries in very-low birthweight children: A case-controlled, longitudinal study. Pediatric Dentistry, 19, 42-49.

[48] Morris, S.S., Victora, C.G., Barros, F.C., Halpern, R., Menezes, A.M., César, J.A., Horta, B.L. and Tomasi, E. (1998) Length and ponderal index at birth: Associations with mortality, hospitalizations, development and postnatal growth in Brazilian infants. International Journal of Epidemiology, 27, 242-247.

http://dx.doi.org/10.1093/ije/27.2.242

[49] Klinger, G., Sirota, L., Lusky, A. and Reichman, B. (2006) Bronchopulmonary dysplasia in very low birth weight infants is associated with prolonged hospital stay. Journal of Perinatology, 26, 640-644. http://dx.doi.org/10.1038/sj.jp.7211580

[50] Fukuda, J.T., Sonis, A.L., Platt, O.S. and Kurth, S. (2005) Acquisition of mutans streptococci and caries prevalence in pediatric sickle cell anemia patients receiving longterm antibiotic therapy. Pediatric Dentistry, 27, 186-190. 